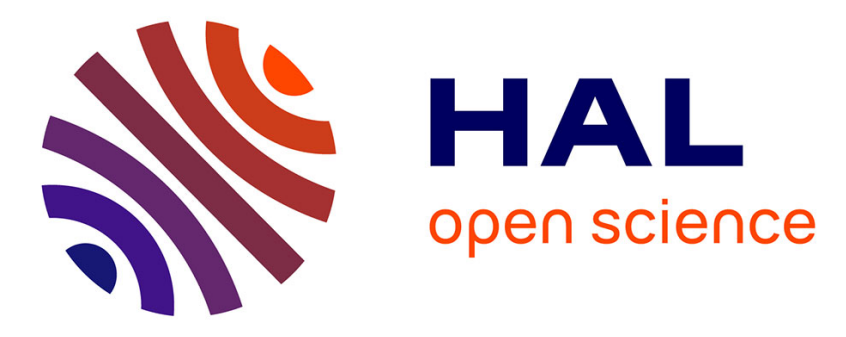

\title{
Coupled chemistry climate model simulations of stratospheric temperatures and their trends for the recent past
}

John Austin, R.J. Wilson, Hideharu Akiyoshi, Slimane Bekki, N. Butchart, Chantal Claud, V.I. Fomichev, P. Forster, R.R. Garcia, N.P. Gillett, et al.

\section{To cite this version:}

John Austin, R.J. Wilson, Hideharu Akiyoshi, Slimane Bekki, N. Butchart, et al.. Coupled chemistry climate model simulations of stratospheric temperatures and their trends for the recent past. Geophysical Research Letters, 2009, 36 (13), pp.L13809. 10.1029/2009GL038462 . hal-00404260

\section{HAL Id: hal-00404260 \\ https://hal.science/hal-00404260}

Submitted on 8 May 2016

HAL is a multi-disciplinary open access archive for the deposit and dissemination of scientific research documents, whether they are published or not. The documents may come from teaching and research institutions in France or abroad, or from public or private research centers.
L'archive ouverte pluridisciplinaire HAL, est destinée au dépôt et à la diffusion de documents scientifiques de niveau recherche, publiés ou non, émanant des établissements d'enseignement et de recherche français ou étrangers, des laboratoires publics ou privés. 


\title{
Coupled chemistry climate model simulations of stratospheric temperatures and their trends for the recent past
}

\author{
J. Austin, ${ }^{1}$ R. J. Wilson, ${ }^{1}$ H. Akiyoshi, ${ }^{2}$ S. Bekki, ${ }^{3}$ N. Butchart, ${ }^{4}$ C. Claud, ${ }^{5}$ \\ V. I. Fomichev, ${ }^{6}$ P. Forster, ${ }^{7}$ R. R. Garcia, ${ }^{8}$ N. P. Gillett, ${ }^{9}$ P. Keckhut, ${ }^{10}$ U. Langematz, ${ }^{11}$ \\ E. Manzini, ${ }^{12}$ T. Nagashima, ${ }^{2}$ W. J. Randel, ${ }^{8}$ E. Rozanov, ${ }^{13}$ K. Shibata, ${ }^{14}$ K. P. Shine,${ }^{15}$ \\ H. Struthers, ${ }^{16}$ D. W. J. Thompson, ${ }^{17}$ F. Wu, ${ }^{8}$ and S. Yoden ${ }^{18}$
}

Received 8 April 2009; revised 28 May 2009; accepted 9 June 2009; published 14 July 2009.

[1] Temperature results from multi-decadal simulations of coupled chemistry climate models for the recent past are analyzed using multi-linear regression including a trend, solar cycle, lower stratospheric tropical wind, and volcanic aerosol terms. The climatology of the models for recent years is in good agreement with observations for the troposphere but the model results diverge from each other and from observations in the stratosphere. Overall, the models agree better with observations than in previous assessments, primarily because of corrections in the observed temperatures. The annually averaged global and polar temperature trends simulated by the models are generally in agreement with revised satellite observations and radiosonde data over much of their altitude range. In the global average, the model trends underpredict the radiosonde data slightly at the top of the observed range. Over the Antarctic some models underpredict the temperature trend in the lower stratosphere, while others overpredict the trends. Citation: Austin, J., et al. (2009), Coupled chemistry climate model simulations of stratospheric temperatures and their trends for the recent past, Geophys. Res. Lett., 36, L13809, doi:10.1029/2009GL038462.

\section{Introduction}

[2] As carbon dioxide concentrations rise, the troposphere is expected to warm and the stratosphere is expected to cool. The stratosphere is therefore an important test bed for the performance of climate models and for providing an early indication of climate change [e.g., Ramaswamy et al., 2001]. Pawson et al. [2000] assessed the performance of 13 climate models with well-resolved stratospheres, but these did not include chemistry, and simulations were on average less than 10 years each. They concluded that the models generally had an overall cold bias compared

\footnotetext{
${ }^{1}$ NOAA Geophysical Fluid Dynamics Laboratory, Princeton, New Jersey, USA.

${ }^{2}$ National Institute for Environmental Studies, Tsukuba, Japan.

${ }^{3}$ Service d'Aeronomie, Institut Pierre-Simon Laplace, Universite Paris VI, CNRS, Paris, France.

${ }^{4}$ Climate Research Division, Met Office, Exeter, UK.

${ }^{5}$ Laboratoire de Météorologie Dynamique/IPSL, CNRS, Ecole Polytechnique, Palaiseau, France.

${ }^{6}$ ESSE, York University, Toronto, Ontario, Canada.

${ }^{7}$ Institute for Atmospheric Science, University of Leeds, Leeds, UK.

${ }^{8}$ Atmospheric Chemistry Division, National Center for Atmospheric Research, Boulder, Colorado, USA.

Copyright 2009 by the American Geophysical Union. 0094-8276/09/2009GL038462
}

with measurements. Temperature trends have been determined from climate models, with and without chemistry [Shine et al., 2003] and were found to be generally consistent with observations in the global average. However, trends were found to be larger than observed by satellite data near $5 \mathrm{hPa}$ and smaller than observed in the lower mesosphere.

[3] Model simulations of the SPARC CCMVal (Stratospheric Processes and their Role in Climate, Chemistry Climate Model Validation) project [Eyring et al., 2005] are investigated. Each model has been run for several decades into the future as well as several decades for the past, using a consistent set of climate forcings across all the models. Here, we focus on the model performance of stratospheric temperature for the past, and the current work can therefore be considered a continuation of the works Pawson et al. [2000] and Shine et al. [2003] using updated observations and longer simulations, including some ensemble simulations, as well as consistent forcings.

\section{Description of the 3-D Models and Simulations Included}

[4] The main model calculations included are the REF1 simulations described by Eyring et al. [2006]. The MRI model used in that work was improved early in this study, and the revised results are included here. The results are from transient simulations for the period 1950 to 2005 or a subset thereof. Table 1 summarizes the models and the periods of integration. All models specified changes in chlorofluorocarbons and halons, from which the active chlorine and bromine amounts were simulated. All models specified the concentrations of the well-mixed greenhouse gases from observations, and specified observed sea

\footnotetext{
${ }^{9}$ Canadian Centre for Climate Modelling and Analysis, Environment Canada, University of Victoria, Victoria, British Columbia, Canada.

${ }^{10}$ Service d'Aeronomie, CNRS, Verrieres-le-Buisson, France.

${ }^{11}$ Institut für Meteorologie, Freie Universität Berlin, Berlin, Germany.

${ }^{12}$ Instituto Nationale di Geofisica e Vulcanologia and Centro EuroMediterraneo per i Cambiamenti Climatici, Bologne, Italy.

${ }^{13} \mathrm{PMOD} / \mathrm{WRC}$ and IAC ETHZ, Davos, Switzerland.

${ }^{14}$ Meteorological Research Institute, Tsukuba, Japan.

${ }^{15}$ Department of Meteorology, University of Reading, Reading, UK.

${ }^{16}$ NIWA, Omakau, New Zealand.

${ }^{17}$ Department of Atmospheric Sciences, Colorado State University, Fort Collins, Colorado, USA.

${ }^{18}$ Department of Geophysics, Kyoto University, Kyoto, Japan.
} 
Table 1. Brief Description of Models and Simulations ${ }^{\mathrm{a}}$

\begin{tabular}{|c|c|c|c|c|c|}
\hline Model & Simulations & Chemical Effects on Aerosols & Radiative Effects of Aerosols & QBO & Model Reference \\
\hline AMTRAC & $3 \times 1960-2004$ & $\mathrm{SADs}^{\mathrm{b}}$ & Optical depths ${ }^{\mathrm{c}}$ & No & Austin and Wilson [2006] \\
\hline CCSRNIES & $1980-2004$ & $\mathrm{SADs}^{\mathrm{d}}$ & Calculated online $\mathrm{e}^{\mathrm{e}}$ & Forced & Akiyoshi et al. [2009] \\
\hline CMAM & $1960-2004$ & $\mathrm{SADs}^{\mathrm{d}}$ & Calculated online & No & de Grandpré et al. [2000] \\
\hline GEOSCCM & $1960-2003$ & No & No & No & Stolarski et al. [2006] \\
\hline LMDZrepro & $1979-1999$ & Modeled SADs & No & No & Jourdain et al. [2008] \\
\hline MAECHAM4-CHEM & $1980-1999$ & $\mathrm{SADs}^{\mathrm{f}}$ & Precalculated ${ }^{\mathrm{g}}$ & Forced & Steil et al. [2003] \\
\hline MRI & $5 \times 1980-2004$ & $\mathrm{SADs}^{\mathrm{d}}$ & Calculated online ${ }^{\mathrm{e}}$ & Internal & Shibata et al. [2005] \\
\hline SOCOL & $1980-2004$ & SADs ${ }^{\mathrm{h}}$ & Calculated online ${ }^{\mathrm{h}}$ & Forced & Egorova et al. [2005] \\
\hline UMETRAC & $1980-1999$ & Calculated online $\mathrm{e}^{\mathrm{e}}$ & Precalculated heating rates ${ }^{\mathrm{c}}$ & Internal & Austin and Butchart [2003] \\
\hline UMSLIMCAT & $1980-1999$ & SADs ${ }^{\mathrm{d}}$ & No & Internal & Tian and Chipperfield [2005 \\
\hline WACCM & $3 \times 1950-2003$ & $\mathrm{SADs}^{\mathrm{d}}$ & No & No & Garcia et al. [2007] \\
\hline
\end{tabular}

${ }^{\mathrm{a}}$ The source of the surface area densities (SADs) and the references used to compute the optical effects of the aerosols are given by the following footnotes.

${ }^{\mathrm{b}}$ From Thomason and Poole [1997].

${ }^{\mathrm{c}}$ From G. Stenchikov (personal communication, 2005).

${ }^{\mathrm{d}}$ From D. Considine (personal communication, 2005).

${ }^{\mathrm{e}}$ From Sato et al. [1993], updated.

f From Jackman et al. [1996].

${ }^{\mathrm{g}}$ From Kirchner et al. [1999].

${ }^{\mathrm{h}}$ From Thomason and Peter [2006].

surface temperature and sea ice as a model lower boundary condition.

\section{Temperature Results}

[5] The zonally averaged temperature data for each model was fitted to the same regression equation as was done by Austin et al. [2008], which included a trend term, tropical wind terms to account for the quasibiennial oscillation, the solar cycle and volcanic aerosol terms. Results are presented for the global average and for the polar regions, where temperatures have an important impact on ozone depletion via polar stratospheric cloud formation.

\subsection{Annually Averaged Temperatures 1990-1999}

[6] To put the model results in the context of previous studies of middle atmosphere performance, in particular Pawson et al. [2000], we show in Figure 1 the globally averaged annual mean temperature as a function of pressure. Data assimilation fields from the United Kingdom Meteorological Office (UKMO) and the European Centre for Medium Range Weather Forecasts Interim analysis are also included. The assimilation fields differ by less than about $2 \mathrm{~K}$ throughout the pressure range indicated in Figure 1. The difference between model results and mean UKMO data assimilation fields are also shown in Figure 1 (bottom). The model results are close together in the troposphere and lower stratosphere, and increasingly diverge above the middle stratosphere, as shown by the difference model observations (Figure 1, bottom). In comparison with the results of Pawson et al., Figure 1 shows better agreement in the troposphere with a smaller range in model temperatures in the middle atmosphere. Unlike in Pawson et al., a cold bias is no longer present, except of about $2 \mathrm{~K}$ in the troposphere. In the stratosphere the models are on average too warm by a similar amount.

\subsection{Globally Averaged Temperature}

[7] In Figure 2 is shown the evolution of the global average annual temperature weighted in the vertical in the same proportion as the Microwave Sounding Unit (MSU) channel 4 radiance, which peaks near $80 \mathrm{hPa}$. The increases in observed temperatures following the eruptions of El Chichón (1983) and Mt. Pinatubo (1991) are clearly apparent. The volcanic responses of the models vary substantially, partly because several models did not include aerosol heating (Table 1). The remaining models are similar to the
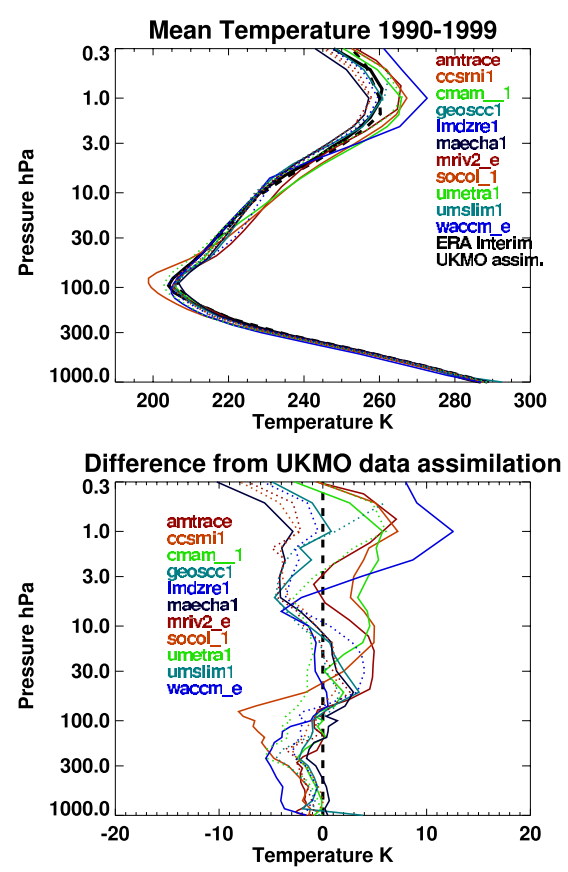

Figure 1. Annually, globally averaged temperatures (K), as a function of pressure, for the period 1990-1999 simulated by the models. The model names are indicated, truncated to the first six characters. The seventh character refers to the simulation number for that model, and e denotes the ensemble mean for the models which completed at least three simulations. UKMO data assimilation analyses for 19911999 are indicated by the thick broken black line. The assimilation results from ERA Interim (1990-1999) are shown by the thick, black solid line. In the list of models, the first 6 models are given by the solid lines, and the next 5 models are given by the dotted lines. 

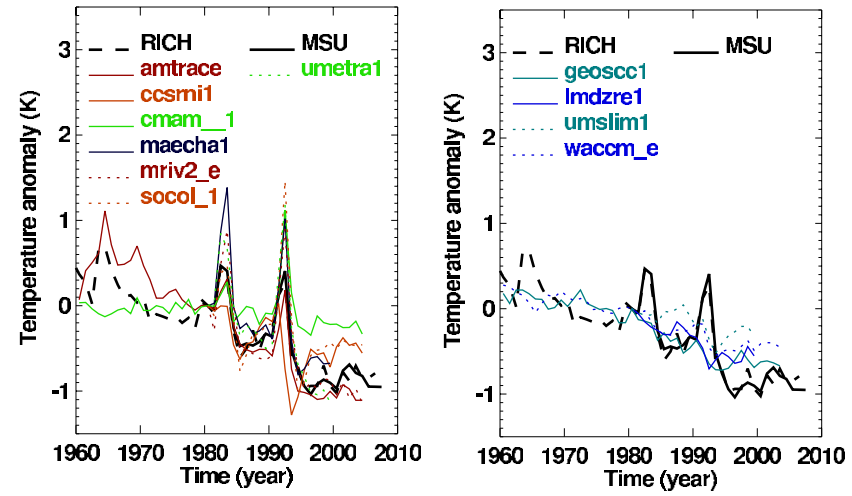

Figure 2. Global, annually averaged temperature time series, weighted in the vertical with the MSU4 channel weighting function. The values derived from the RICH radiosonde data [Haimberger et al., 2008] are indicated by the thick broken black line. See Randel et al. [2009] for a comparison with other radiosonde datasets. MSU data are given by the bold black line. The plotted values are anomalies relative to the 1980 mean, applied individually to each data source.(left) Those models (7) which contain volcanic aerosol heating. (right) Those models (4) which exclude heating from this source.

results of Cordero and de Forster [2006], which also indicated that the simulated response to the eruptions varied substantially between models. The observed long term trends are generally larger than simulated by the models, but those models which included aerosol effects (Figure 2, left) show the general behavior of a warming during the eruptions and a rapid cooling thereafter followed by an approximate stabilization, as also discussed by Ramaswamy et al. [2006].

[8] Temperature trends for the periods 1960-1979 and 1980-1999 are very different (Figures 3a and 3b). Stratospheric cooling was larger during the later period due to ozone depletion, although there is a larger range in the model results due to more models being included and more widely varying ozone trends [Eyring et al., 2006]. The smallest temperature trend in the stratosphere is provided by the CMAM which was found to be related to a problem with the middle atmosphere radiation scheme that underestimated the impact of the $\mathrm{CO} 2$ increase. The scheme has now been corrected.

[9] The results are similar to Shine et al. [2003, Figure 4], in which model ozone trends were specified from observations, although in our results the lower stratospheric cooling peaks at a slightly higher amount in some models. In Shine et al. the discrepancy between Stratospheric Sounding Unit (SSU) data and models was large near $5 \mathrm{hPa}$. However, the SSU data have recently been corrected for the increase in atmospheric $\mathrm{CO}_{2}$ concentrations [Shine et al., 2008; Randel et al., 2009] and this has led to improved agreement between observations and model results.

\subsection{Polar Temperature Trends}

[10] The simulated temperature trends polewards of $67^{\circ} \mathrm{N}$ (Figure 3c) have many of the features of the global trend (Figure 3b) but with much larger model variability. The near surface warming trends are typically larger in magnitude than the global average. Lower stratospheric trends for the period 1960 to 1979 are small (not shown), and in the 1980 to 1999 period, the switch between tropospheric warming
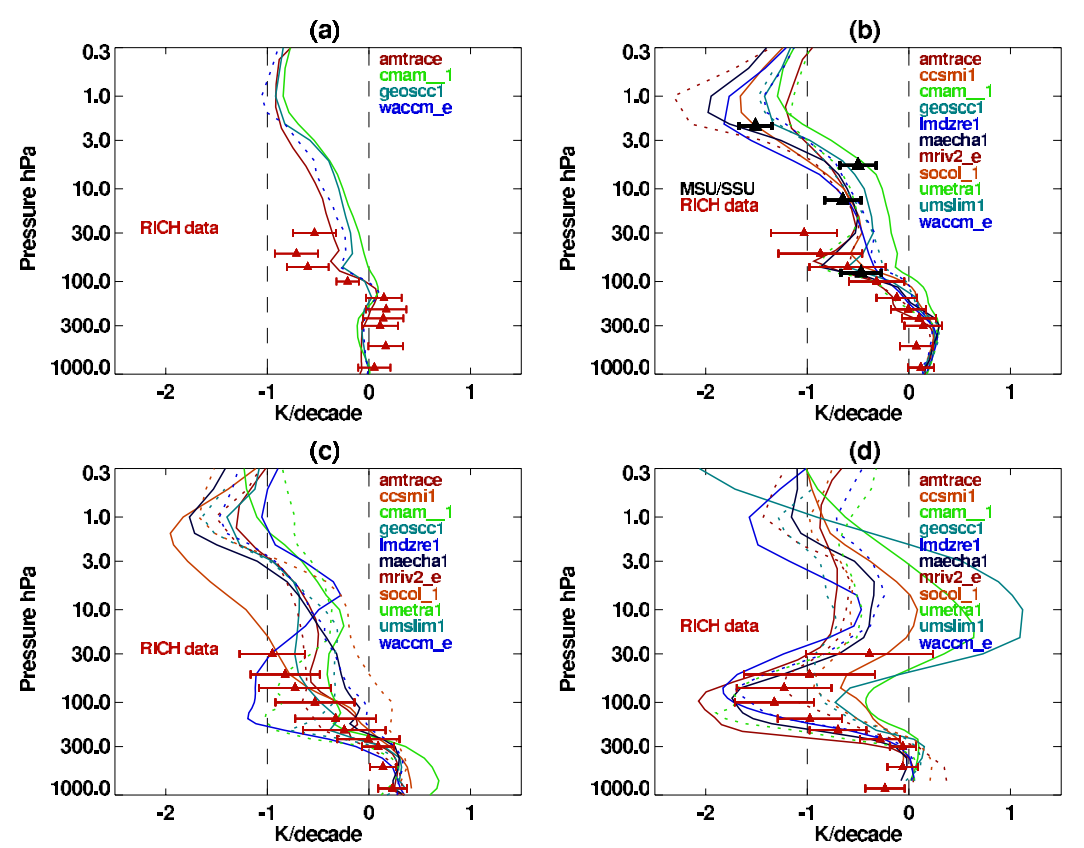

(c)

(a)
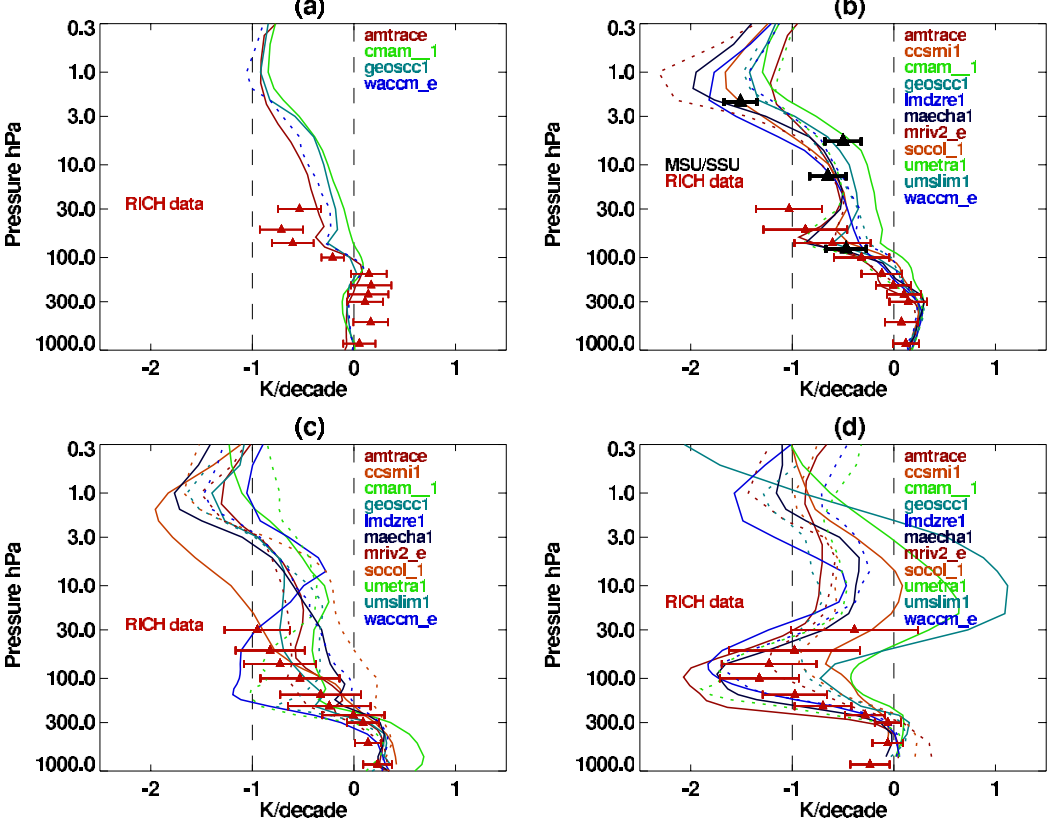

Figure 3. Annually averaged temperature trends (K/decade) simulated by the models: (a) and (b) global, for the periods 1960-1979 and 1980-1999. Trends from Microwave Sounding Unit and Stratospheric Sounding Unit averaged over the latitude range $70^{\circ} \mathrm{S}$ to $70^{\circ} \mathrm{N}$ are included (black triangles) for the period 1980 to 1999 . Radiosonde trends are from the RICH dataset [Haimberger et al., 2008] with $\pm 2 \sigma$ uncertainty ranges. See Figure 2 for color key for the model results. (c) and (d) the polar $\left(67^{\circ}-90^{\circ}\right.$ latitude) trends in the Arctic and Antarctic are shown for the period 1980-1999 and in contrast to Figures $3 \mathrm{a}$ and $3 \mathrm{~b}$ the $\mathrm{RICH}$ data are given with $\pm 1 \sigma$ uncertainty ranges for clarity. 
and stratospheric cooling near $300 \mathrm{hPa}$ is a consistent feature of all but one of the models. Nonetheless, the stratospheric cooling rates themselves vary substantially from one model to the next. In the lower stratosphere that variability is particularly large, with model internal variability most likely having a major contribution. The models in general agree with trends derived from radiosondes [Haimberger et al., 2008; Randel et al., 2009], although both models and observations cover a wide possible range. Above about $50 \mathrm{hPa}$, the models typically show a trend which decreases with height, or remains approximately constant to the middle stratosphere, although the radiosonde data indicate an increasing negative trend to the top of their range.

[11] The temperature trend results polewards of $67^{\circ} \mathrm{S}$ (Figure 3d) indicate that significant tropospheric warming is absent from most models in contrast to the Arctic. This is likely due to the radiative-dynamical effect of the ozone hole [Thompson and Solomon, 2002]. For most models, though, the Antarctic temperature trend is similar to the global average, but with enhanced cooling near $100 \mathrm{hPa}$. The models agree with radiosonde observations in the troposphere, with near zero trends, but in the lower stratosphere there is a large divergence of results, probably due to the differences in the simulated ozone holes which varied in area and depth in the different models. At the altitude of peak cooling, several models appear to underpredict its magnitude, but there are large uncertainties in the rate in both models and observations.

\section{Discussion and Conclusion}

[12] We have examined temperature variations and trends in a number of coupled chemistry climate model simulations which were commissioned as part of the 2006 Ozone Assessment [World Meteorological Organization, 2007, chap. 5 and 6]. In the lower stratosphere the simulations were generally consistent with previous work, with increases in temperature during volcanic eruptions [e.g., Cordero and de Forster, 2006], that vary substantially among models, and with step-like features after the eruptions [Ramaswamy et al., 2006]. There is therefore a need in future simulations to treat aerosols in a more realistic manner to try to simulate the volcanic impact in better quantitative agreement with observations.

[13] The model globally averaged temperatures agreed better with observations than previous assessments [e.g., Pawson et al., 2000]. This is likely to be related to a number of factors, including a slightly colder climatology of the observations, a more carefully controlled set of simulations with standardized forcings, as well as genuine improvements in model performance.

[14] Trends in the globally averaged temperature were compared with corrected Stratospheric Sounding Unit data [Shine et al., 2008; Randel et al., 2009]. Discrepancies with observations, previously noted for those models which included ozone trends [Shine et al., 2003] have been reduced. This has occurred primarily because of corrections in the observed temperatures leading to reduced trends in the lower mesosphere and enhanced trends in the stratosphere.

[15] Differences in model formulation and in the simulation of ozone trends likely contribute to the spread in calculated lower stratospheric temperature trends. However, the Arctic is especially prone to variability in the dynamics and this natural variability is reflected in model performance, as well as observed trends.

[16] Acknowledgments. We would like to thank Dan Schwarzkopf and Stuart Freidenreich (GFDL) for comments on the manuscript prior to submission. An anonymous reviewer and Markus Rex are thanked for helping to improve the paper. The European Centre for Medium Range Weather Forecasts supplied data, and Ingo Wohltman is thanked for providing additional processing. GEOSCCM data were kindly supplied via the CCMVal project.

\section{References}

Akiyoshi, H., L. B. Zhou, Y. Yamashita, K. Sakamoto, M. Yoshiki, T. Nagashima, M. Takahashi, J. Kurokawa, M. Takigawa, and T. Imamura (2009), A CCM simulation of the breakup of the Antarctic polar vortex in the years 1980-2004 under the CCMVal scenarios, J. Geophys. Res., 114, D03103, doi:10.1029/2007JD009261.

Austin, J., and N. Butchart (2003), Coupled chemistry-climate model simulations for the period 1980 to 2020: Ozone depletion and the start of ozone recovery, Q. J. R. Meteorol. Soc., 129, 3225-3249.

Austin, J., and R. J. Wilson (2006), Ensemble simulations of the decline and recovery of stratospheric ozone, J. Geophys. Res., 111, D16314, doi:10.1029/2005JD006907.

Austin, J., et al. (2008), Coupled chemistry-climate model simulations of the solar cycle in ozone and temperature, J. Geophys. Res., 113, D11306, doi:10.1029/2007JD009391.

Cordero, E. C., and P. M. de Forster (2006), Stratospheric variability and trends on models used for the IPCC AR4, Atmos. Chem. Phys., 6 , $5369-5380$

de Grandpré, J., S. R. Beagley, V. I. Fomichev, E. Griffioen, J. C. McConnell, A. S. Medvedev, and T. G. Shepherd (2000), Ozone climatology using interactive chemistry: Results from the Canadian Middle Atmosphere Model, J. Geophys. Res, 105, 26,475-26,492.

Egorova, T., E. Rozanov, V. Zubov, E. Manzini, W. Schmutz, and T. Peter (2005), Chemistry-climate model SOCOL: A validation of the present-day climatology, Atmos. Chem. Phys., 5, 1557-1576.

Eyring, V., et al. (2005), A strategy for process-oriented validation of coupled chemistry-climate models, Bull. Am. Meteorol. Soc., 86, $1117-1133$.

Eyring, V., et al. (2006), Assessment of temperature, trace species and ozone in chemistry-climate model simulations of the recent past, J. Geophys. Res., 111, D22308, doi:10.1029/2006JD007327.

Garcia, R. R., D. R. Marsh, D. E. Kinnison, B. A. Boville, and F. Sassi (2007), Simulation of secular trends in the middle atmosphere 19502003, J. Geophys. Res., 112, D09301, doi:10.1029/2006JD007485.

Haimberger, L., C. Tavolato, and S. Sperka (2008), Toward elimination of the warm bias in historic radiosone temperature records: Some new results from a comprehensive intercomparison of upper air data, J. Clim., $21,4587-4606$

Jackman, C. H., E. L. Fleming, S. Chandra, D. B. Considine, and J. E. Rosenfield (1996), Past, present, and future modeled ozone trends with comparisons to observed trends, J. Geophys. Res., 101, 28,75328,768 .

Jourdain, L., S. Bekki, F. Lott, and F. Lefévre (2008), The coupled chemistry climate model LMDz Reprobus: Description of a transient simulation of the period 1980-1999, Ann. Geophys., 26, 1391-1413.

Kirchner, I., G. L. Stenchikov, H.-F. Graf, A. Robock, and J. C. Antuña (1999), Climate model simulation of winter warming and summer cooling following the 1991 Mount Pinatubo eruption, J. Geophys. Res., 104, 19,039-19,055

Pawson, S., et al. (2000), The GCM-reality intercomparison project for SPARC (GRIPS): Scientific issues and initial results, Bull. Am. Meteorol. Soc., 81, 781-796.

Ramaswamy, V., et al. (2001), Stratospheric temperature trends observations and model simulations, Rev. Geophys., 39, 71-122.

Ramaswamy, V., M. D. Schwarzkopf, W. J. Randel, B. D. Santer, B. J. Soden, and G. L. Stenchikov (2006), Anthropogenic and natural influences in the evolution of lower stratospheric cooling, Science, 311, $1138-1141$

Randel, W. J., et al. (2009), An update of observed stratospheric temperature trends, J. Geophys. Res., 114, D02107, doi:10.1029/ 2008JD010421.

Sato, M., J. E. Hansen, M. P. McCormick, and J. B. Pollack (1993), Stratospheric aerosol optical depths, 1850-1990, J. Geophys. Res., 98, 22,987-22,994

Shibata, K., M. Deushi, T. T. Sekiyama, and H. Yoshimura (2005), Development of an MRI chemical transport model for the study of stratospheric chemistry, Pap. Meteorol. Geophys., 55, 75-119. 
Shine, K. P., et al. (2003), A comparison of model-simulated trends in stratospheric temperatures, Q. J. R. Meteorol. Soc., 129, 1565-1588.

Shine, K. P., J. J. Barnett, and W. J. Randel (2008), Temperature trends derived from stratospheric sounding unit radiances: The effect of increasing $\mathrm{CO}_{2}$ on the weighting function, Geophys. Res. Lett., 35, L02710, doi:10.1029/2007GL032218.

Steil, B., C. Brühl, E. Manzini, P. J. Crutzen, J. Lelieveld, P. J. Rasch, E. Roeckner, and K. Krüger (2003), A new interactive chemistry-climate model: 1. Present-day climatology and interannual variability of the middle atmosphere using the model and 9 years of HALOE/UARS data, J. Geophys. Res., 108(D9), 4290, doi:10.1029/2002JD002971.

Stolarski, R. S., A. R. Douglass, S. Steenrod, and S. Pawson (2006), Trends in stratospheric ozone: Lessons learned from a 3D chemical transport model, J. Atmos. Sci., 63, 1028-1041.

Thomason, L. W., and T. Peter (Eds.) (2006), Assessment of stratospheric aerosol properties (ASAP), SPARC Rep. 4, WMO/TD 1295, Tech. Rep. $W C R P-124$, World Clim. Res. Program, Geneva, Switzerland.

Thomason, L. W., and L. R. Poole (1997), A global climatology of stratospheric aerosol surface area density deduced from Stratospheric Aerosol and Gas Experiment II measurements: 1984-1994, J. Geophys. Res., 102, 8967-8976.

Thompson, D. W. J., and S. Solomon (2002), Interpretation of recent Southern Hemisphere climate change, Science, 296, 895-899.

Tian, W., and M. P. Chipperfield (2005), A new coupled chemistry-climate model for the stratosphere: The importance of coupling for future $\mathrm{O}_{3}$ climate predictions, Q. J. R. Meteorol. Soc., 131, 281-304.

World Meteorological Organization (2007), Scientific assessment of ozone depletion: 2006, Global Ozone Res. Monit. Proj. Rep. 50, Geneva, Switzerland.

H. Akiyoshi and T. Nagashima, National Institute for Environmental Studies, 16-2 Onogawa, Tsukuba-shi, Ibaraki, 305-0053, Japan.

J. Austin and J. Wilson, Geophysical Fluid Dynamics Laboratory, Princeton, NJ 08542-0308, USA. (john.austin@noaa.gov)
S. Bekki, Service d'Aeronomie, Institut Pierre-Simon Laplace, Universite Paris VI, CNRS, Boite 102, Tour 45-46, 3ème etage, 4 place Jussieu, F-75252 Paris CEDEX 05, France.

N. Butchart, Climate Research Division, Met Office, FitzRoy Road, Exeter EX1 3PB, UK

C. Claud, Laboratoire de Météorologie Dynamique/IPSL, CNRS, Ecole Polytechnique, F-91128 Palaiseau CEDEX, France.

V. I. Fomichev, ESSE, York University, 4700 Keele Street, Toronto, ON M3J 1P3, Canada.

P. Forster, Institute for Atmospheric Science, University of Leeds, Leeds LS2 9JT, UK

R. R. Garcia, W. J. Randel, and F. Wu, Atmospheric Chemistry Division, National Center for Atmospheric Research, P.O. Box 3000, Boulder, CO 80307-3000, USA.

N. P. Gillett, Canadian Centre for Climate Modelling, University of Victoria, P.O. Box 3065, STN CSC, Victoria, BC V8W 3V6, Canada.

P. Keckhut, Service d'Aeronomie, CNRS, BP 3, F-91371 Verrieresle-Buisson CEDEX, France.

U. Langematz, Institut für Meteorologie, Freie Universität Berlin, CarlHeinrick-Becker-Weg 6-10, D-12165 Berlin, Germany.

E. Manzini, Instituto Nationale di Geofisica e Vulcanologia, I-40128 Bologna, Italy.

E. Rozanov, PMOD/WRC, Dorfstrasse 33, CH-7260 Davos, Switzerland.

K. Shibata, Meteorological Research Institute, 1-1 Nagamine, Tsukuba, Ibaraki, 305-0052, Japan.

K. P. Shine, Department of Meteorology, University of Reading, Earley Gate, P.O. Box 243, Reading RG6 6BB, UK

H. Struthers, NIWA, Private Bag 50061, Omakau 9352, Central Otago, New Zealand.

D. Thompson, Department of Atmospheric Sciences, Colorado State University, Fort Collins, CO 80523, USA.

S. Yoden, Department of Geophysics, Kyoto University, Kyoto, 606-8502, Japan. 